\title{
Kinetics and Mechanism for the Reaction of 4-Nitrophenyl 2-Thiophenecarboxylate with Secondary Alicyclic Amines
}

\author{
Ik-Hwan Um, Eun-Ju Lee, and Jong-Pal Lee ${ }^{*}$ \\ Department of Chemistry, Enha Homans Lniversitv, Seoul 120-750, Korea \\ Department of Chemistry: Dong-A Chinersitv, Pusan 604-714, Korea \\ Received October 10, 2001
}

\begin{abstract}
Second-order-rate constants $\left(k_{\mathrm{N}}\right)$ have been measured spectrophotometrically for the reactions of 4-nitrophenyl 2-thiophenecarboxylate (1a) with a series of secondary alicyclic amines in $\mathrm{H}_{2} \mathrm{O}$ containing 20 mole \% DMSO at $25.0^{\circ} \mathrm{C}$. The ester 1 a is less reactive than 4-nitrophenyl 2 -furoate $(\mathbf{l b})$ but more reactive than 4-nitrophenyl benzoate (1c) except towards piperazinium ion. The Bronsted-type plots for the aminolyses of $\mathbf{1 a}, \mathbf{1 b}$ and $\mathbf{1 c}$ are linear with a $\beta_{\text {ul }}$ value of 0.92 .0 .84 and 0.85 , respectively. indicating that the replacement of the $\mathrm{CH}=\mathrm{CH}$ group by a sulfur or an oxygen atom in the benzoyl moiety of $1 \mathrm{c}$ does not cause any mechanism change. The reaction of piperidine with a series of substituted phenyl 2-thiophenecarboxylates gives a linear Hammett plot with a large $\rho^{-}$value $\left(\rho^{-}=3.11\right)$ when $\sigma^{-}$constants are used. The linear Bronsted and Hammett plots with large $\beta_{m u}$ and $\rho^{-}$values suggest that the aminolysis of 1a proceeds via rate-determining break-down of the addition intermediate to the products.
\end{abstract}

Keywords : Aminolysis, Rate-determining step, Mechanism, Hammett equation.

\section{Introduction}

Reactions of amines with carbonyl compounds have intensively been investigated due to importance in chemistry as well as in biological processes ${ }^{1-5}$ The reaction mechanism for aminolysis of carboxylic esters has been suggested to proceed through an addition intermediate in which the ratedetermining-step (RDS) is dependent on the basicity of the leaving group and the nucleophilic amine. ${ }^{-5}$ Linear free energy relationship such as Bronsted or Hammett equation has been the most popular probe to investigate the reaction mechanism. ${ }^{6}$ Nonlinear Bronsted-type plot has often been observed for aminolysis of carbosylic esters with a good leaving group. and has been attributed to a change in the RDS of a stepwise mechanism upon changing the basicity of the leaving group or the nucleophilic amines. ${ }^{1-3}$

However, most studies have been directed to investigate the reaction mechanism by changing the basicity of leaving group and incoming amines. The effect of the acyl moiety of carboxylic esters on reaction rates and mechanism has rarely

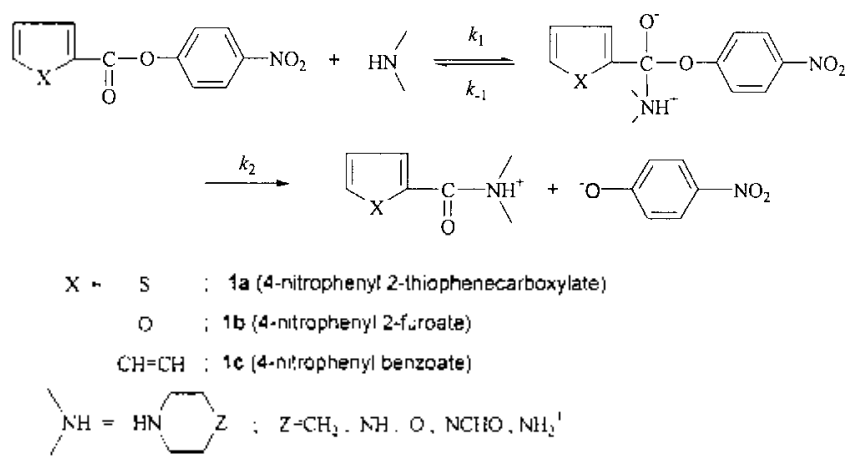

Scheme 1 been investigated. ${ }^{7.9}$ Therefore, we have recently performed aminolyses of carboxylic esters having various acyl moiety, such as acetyl, phenylacetyl and substituted benzoyl groups. ${ }^{7}$ In order to expand our study to the effect of acyl moiety on rates and reaction mechanism, we have introduced a heteroaromatic ring by replacing the $\mathrm{CH}=\mathrm{CH}$ group in the benzoyl moiety by a sulfur or an oxygen atom as shown in Scheme I, and performed aminolysis reactions with a series of secondary alicyclic amines. We have also investigated the effect of leaving group on reaction rates in order to get further information about the reaction mechanism

\section{Experimental Section}

Materials. Aryl 2-thiophenecarboxylates were easily prepared from the reaction of 2-thiophenecarboxyl chloride and a corresponding phenol in the presence of triethylamine in metlyylene chloride. DMSO and all the amines used were of the highest quality available from Aldrich. Doubly glass distilled water was further boiled and cooled under nitrogen just before use.

Kinetics. Kinetic studies were performed using a Hewlett Packard 8452A Diode Array UV-Vis Spectrophotometer with a Shimadzu TB-85 model constant temperature circullating bath to keep the temperature in the reaction cell at $25.0 \pm 0.1^{\circ} \mathrm{C}$. The reactions were followed by monitoring the appearance of the leaving group (substituted phenoxides or phenols). All the reactions were performed under pseudofirst-order conditions in which the amine concentrations were at least 20 times in excess over the substrate concentration. The amine stock solution $c a .0 .2 \mathrm{M}$ was prepared by dissolving two equivalent amounts of free amine and one equivalent amount of $\mathrm{HCl}$ solution to keep the $\mathrm{pH}$ constant by making a self buffered solution. The reaction medium 
Table 1. Experinental conditions and pseudo-first-order rate constants $\left(k_{\mathrm{abs}}\right)$ for aminolyses of $p$-nitrophenyl 2-thiophenecarbosylate (1a) in $\mathrm{H}_{2} \mathrm{O}$ containing 20 mole \% DMSO at $25.0 \pm 0.1^{\circ} \mathrm{C}$

\begin{tabular}{lcc}
\hline Amines $(\mathrm{Z})$ & {$[>\mathrm{NH}] / 10^{-3}, \mathrm{M}$} & $k_{\mathrm{oss}} / 10^{-3}, \mathrm{~s}^{-1}$ \\
\hline piperidine $(\mathrm{CH})$ & $0.79-3.89$ & $3.41-21.6$ \\
piperazine $(\mathrm{NH})$ & $0.79-3.89$ & $0.58-3.65$ \\
monplinoline $(\mathrm{O})$ & $3.89-18.1$ & $0.33-1.60$ \\
l-fonmylpiperazine $\left(\mathrm{NCHO}^{+}\right)$ & $14.7-38.5$ & $0.11-0.30$ \\
piperazinium ion $\left(\mathrm{NH}_{2}{ }^{+}\right)$ & $14.7-38.5$ & $0.0012-0.0088$ \\
\hline
\end{tabular}

was $\mathrm{H}_{2} \mathrm{O}$ containing 20 mole \% dimethyl sulfoxide (DMSO) due to the low solubility of the substrates in $\mathrm{H}_{2} \mathrm{O}$. All the solutions were prepared freshly just before use under nitrogen and transferred by Hamilton gas-tight syringes. The effect of ionic strength on rates was observed to be negligible in the present system. Other details in kinetic methods were similar to the ones described previously.

\section{Results}

The kinetic studies were performed spectrophotometrically. All the reactions in the present study obeyed psendofirst-order kinetics over $90 \%$ of the total reaction. Psendofirst-order rate constants $\left(k_{\mathrm{obb}}\right)$ were obtained from the slope of the linear plot of $\ln \left(A *-A_{t}\right)$ ws. time. In Table 1 are sumumarized the kinetic conditions and results. Figure 1 demonstrates linear plots of $k_{\mathrm{obs}} w$. anine concentration. indicating that general base catalysis is absent in the present

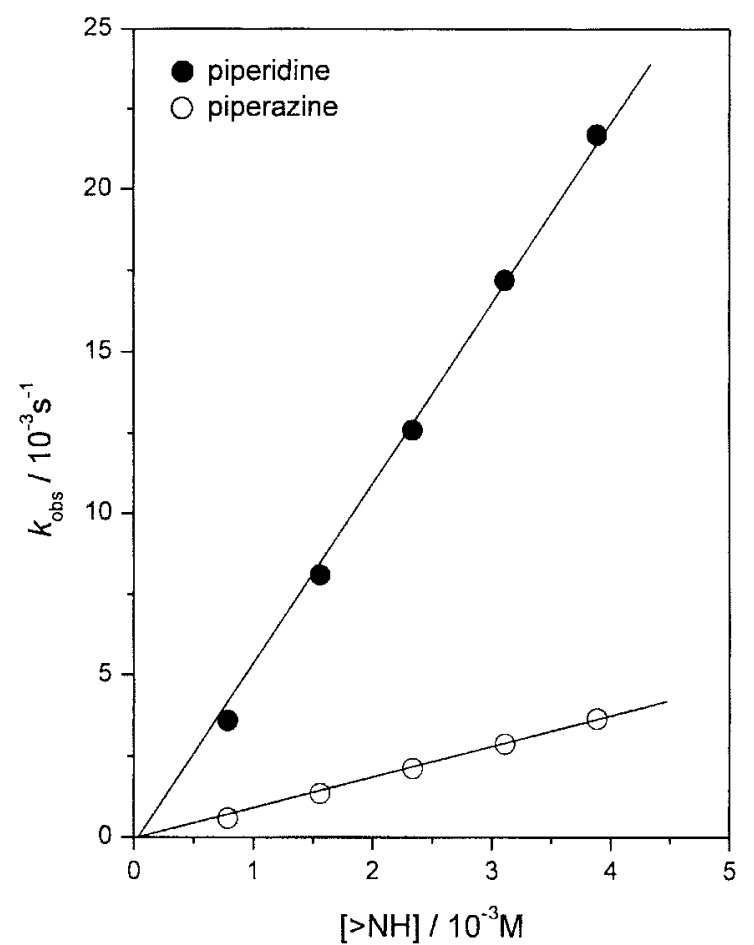

Figure 1. Plots showing linear dependence of $k_{\text {obs }}$ on annine concentrations for the reaction of 4-nitrophenyl 2-thiophenecarboxylate (1a) with piperidine (•) and piperazine (- $)$ in $\mathrm{H}_{2} \mathrm{O}$ containing 20 mole $\%$ DMSO at $25.0 \pm 0.1$ " $\mathrm{C}$.
Table 2. Summary of second-order rate constants ( $h$ ) for aminolyses of 4-nitrophenyl 2-thiophenecarboxylate (1a), 4-nitrophenyl 2-furoate (1b) and 4-nitrophenyl benzoate ( 1 c) in $\mathrm{H}_{2} \mathrm{O}$ containing 20 mole \% DMSO at $25.0 \pm 0.1^{\circ} \mathrm{C}^{a}$

\begin{tabular}{lcccc}
\hline \multirow{2}{*}{ Amines } & \multirow{2}{*}{$K_{\mathrm{a}}$} & \multicolumn{3}{c}{$10 . \mathrm{k}_{\mathrm{N}}, \mathrm{M}^{-1} \mathrm{~s}^{-1}$} \\
\cline { 3 - 5 } & & $\mathbf{1 a}$ & $\mathbf{1 b}^{b}$ & $1 \mathbf{c}^{b}$ \\
\hline 1. piperidine & 11.02 & 59.1 & 253 & 52.9 \\
2. 3-methyl piperidine & 10.8 & - & - & 35.5 \\
3. piperazine & 9.85 & 9.90 & 41.1 & 8.41 \\
4. morpholine & 8.65 & 0.890 & 5.30 & 0.841 \\
5. 1-fomnylpiperazine & 7.98 & 0.083 & 0.733 & - \\
6. piperazinium ion & 5.98 & 0.0032 & 0.0290 & 0.00466 \\
\hline
\end{tabular}

${ }^{a} \mathrm{pH}_{\mathrm{a}}$ data taken from ref. 14. " Rate constants taken from ref. $7 \mathrm{~b}$.

aminolyses. Second-order rate constants $\left(k_{\mathrm{N}}\right)$ were calculated from the slope of the linear plots of $k_{\mathrm{vbs}} v \mathrm{~s}$. amine concentrations. Generally five different amine concentrations were used to calculate $k_{\mathrm{K}}$. values. It is estimated from replicate runs that the uncertainty in any particular measured rate constant is less than $\pm 3 \%$. The $k \mathrm{v}$ values for the aminolyses of 1a are summarized in Table 2 together with the data for the corresponding reactions with $1 \mathrm{~b}$ and $\mathbf{1 c}$ for $\mathbf{a}$ comparison purpose. Figure 2 illustrates the Bronsted-type plots for the aminolyses of 1a-c. In Table 3 are summarized the second-order rate constants for the reaction of piperidine

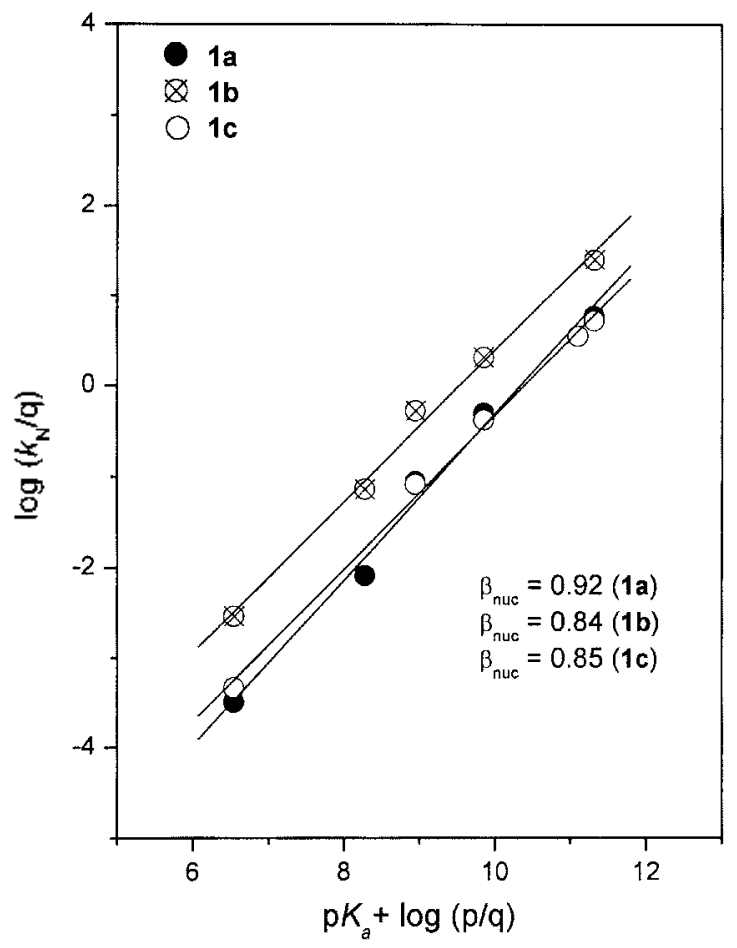

Figure 2. Bronsted-type plots for the reaction of 4-nitrophenyl 2thiophenecarboxylate (1a), 4-nitropheny 12 -furoate (1b) and benzoate (1c) with a series of secondary alicyclic amines in $\mathrm{H}_{2} \mathrm{O}$ containing 20 mole \% DMSO at $25.0 \pm 0.1^{\circ} \mathrm{C}$. The values of $\log k_{\mathrm{k}}$ and $\mathrm{pK}_{\mathrm{a}}$ are statistically conected by using $\mathrm{p}$ and $\mathrm{q}$, e.g., $\mathrm{p}=2$ (except $p=4$ for piperazinium ion, and $q=1$ (except $q=2$ for piperazine) for all the amines studied. 
Table 3. Summary of second-order rate constants for reactions of Y-substituted pheny 1 2-thiophenecarbonsy late (S) and Y-substituted phenyl 2-furoate (O) with piperidine in $\mathrm{H}_{2} \mathrm{O}$ containing 20 mole $\%$ DMSO at $25.0 \pm 0.1^{\circ} \mathrm{C}^{\pi}$

\begin{tabular}{lcccc}
\hline & \multirow{2}{*}{$\sigma^{-}$} & $\sigma$ & \multicolumn{2}{c}{$k_{\mathrm{N}}, \mathrm{M}^{-1} \mathrm{~s}^{-1}$} \\
\cline { 4 - 5 } & & & \multicolumn{1}{c}{$\mathrm{S}$} & $\mathrm{O}$ \\
\hline $4-\mathrm{NO}_{2}$ & 1.27 & 0.78 & 5.88 & 25.3 \\
$4-\mathrm{CHO}$ & 1.13 & 0.42 & 0.96 & 4.79 \\
$4-\mathrm{COCH} \mathrm{H}_{3}$ & 0.87 & 0.50 & 0.26 & 1.90 \\
$4-\mathrm{Cl}$ & 0.23 & 0.23 & 0.0025 & 0.019 \\
\hline
\end{tabular}

${ }^{2} \sigma$ and $\sigma$ constants taken from ref. 16 .

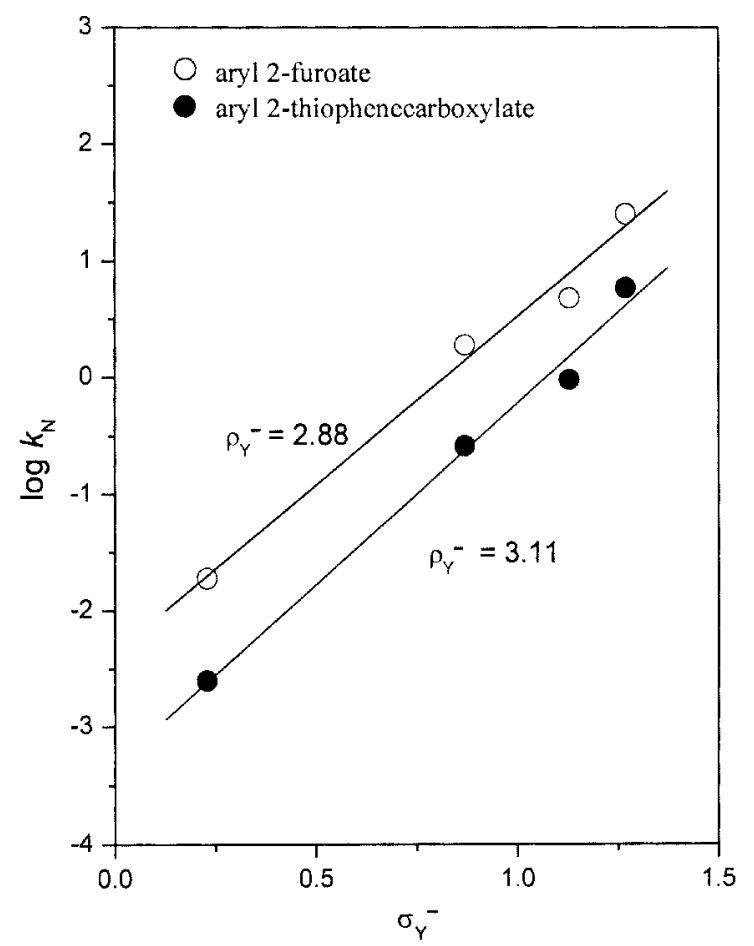

Figure 3. Hammett plots for the reactions of Y-substituted phenyl 2-thiophenecarboxylate ( $)$ and Y-substituted phenyl 2-furoate (a) with piperidine in $\mathrm{H}_{2} \mathrm{O}$ containing 20 mole $\%$ DMSO at 25.0 $\pm 0.1{ }^{\circ} \mathrm{C}$

with a series of substituted phenyl 2-thiophenecarboxy lates. Figure 3 exhibits linear Hammett plots for the reaction of piperidine with substituted phenyl 2-thiopenecarboxylates and with substituted phenyl 2-furoate.

\section{Discussion}

As shown in Table 2. 1a is much less reactive than $\mathbf{1 b}$. One night attribute the difference in their reactivity to the difference in acidity between their parent acids. 2-thiophenecarboxylic acid $\left(\mathrm{p} K_{\mathrm{a}}=3.53\right.$ ) and 2 -furoic acid $\left(\mathrm{p} K_{\mathrm{a}}=3.16\right)^{11}$ A sunilar argument can be applied to the difference in reactivity between $\mathbf{1 a}$ and $\mathbf{1 c}$. since $\mathbf{1 a}$ is more reactive than 1c except towards piperazinium ions and 2-thiophenecarboxylic acid is a stronger acid than benzoic acid by 0.67 $\mathrm{p} K_{a}$ units. Therefore. one can propose that the replacement of $\mathrm{CH}=\mathrm{CH}$ by a sulfur $(\mathbf{1 c} \rightarrow \mathbf{1 a})$ or an oxygen atom $(\mathbf{1 c} \rightarrow$ 1b) in the acyl moiety of $1 \mathrm{c}$ influences not only the acidity of their parent acids but also the reactivity of these esters. This argument is consistent with our recent report that the reactivity of 4-nitrophenyl substituted benzoates towards a series of secondary alicyclic anines increases as the substituent in the acyl moiety becomes a stronger acid strengthening group (e.g.. a stronger electron withdrawing group). ${ }^{7 / 4}$

Table 2 shows that the reactivity of amines increases with increasing amine basicity, e.g. the second-order rate constant for the reaction of $1 \mathrm{a}$ increases from $3.2 \times 10^{-2} \mathrm{M}^{-1} \mathrm{~s}^{-1}$ to $59.1 \mathrm{M}^{-1} \mathrm{~s}^{-1}$ as the $\mathrm{p} K_{4}$ of the conjugate acid of the amine increases from 5.98 for piperazinium ion to 11.02 for piperidine. The effect of amine basicity on the reactivity of 1a-c is demonstrated in Figure 2. One can see linear Bronsted-type plots in all cases. Such linear Bronsted-type plots suggest that there is no mechanism change upon changing amine basicity for the present aminolyses of $1 \mathbf{a - c}$.

A break or a curvature in a Bronsted-type plot has often been observed for aninolysis of esters with a good leaving group (e.g.. 2.4-dinitrophenoxide and 4-nitrothiophenoxide) as the amine basicity increases significantly. i.e., the slope of the plot decreases from a large $\left(\beta_{\text {unc }}=0.8 \pm 0.3\right.$ ) to a small one $\left(\beta_{\text {tuc }}=0.3 \pm 0.1\right){ }^{1.3}$ The position of such a break or a curvature in a Bronsted-type plot $\left(\mathrm{p} K_{4}\right)$ has been reported to occur when the incoming amine becomes more basic than the leaving group by $c a .4-5 \mathrm{p} K_{4}$ units. ${ }^{1 \cdot 3.12}$ Such a nonlinear Bronsted-type plot has been suggested as evidence for a change in the RDS. i.e., from breakdown of the addition intemediate to the products (the $k_{2}$ step in Scheme 1) to formation of the intermediate (the $k_{1}$ step in Scheme 1). ${ }^{1.2 .12}$ The $\mathrm{p} K_{\mathrm{a}}$ of the conjugate acid of the leaving group (4nitrophenoxide ion) is 7.14 , and the most basic amine used in the present system is piperidine whose $p K_{a}$ is 11.02 . Although piperidine is more basic than the leaving 4 nitrophenoxide ion. the difference in their basicity is smaller than $4 \mathrm{p} K_{\text {a }}$ units. Therefore. a change in the RDS upon changing amine basicity would not be expected to occur for the present aminolysis.

One can obtain useful information about the reaction mechanism from the magnitude of $\beta_{\text {uc }}$ values. The magnitude of $\beta_{\text {muc }}$ value has been calculated to be $0.92,0.84$ and 0.85 for the aminolysis of $1 \mathbf{a}, 1 \mathbf{b}$ and $1 \mathrm{c}$, respectively. Such a large $\beta_{\text {nuc }}$ value indicates that the aminolysis of 1a-c proceeds through a rate-determining breakdown of the addition intermediate to the products. The magnitude of $\beta_{\text {nuc }}$ value has also been suggested to represent the degree of the effective charge developed on the $\mathrm{N}$ atom at the transition state (TS) of aminolysis reactions. ${ }^{12-14}$ Therefore. one might consider the positive charge developed on the $\mathrm{N}$ atom at the TS is slightly more significant for the reaction of 1a than that of $1 \mathbf{b}$ or $1 \mathrm{c}$. based on their $\beta_{\text {tuc }}$ values.

In order to obtain more information about the reaction mechanism and the TS structure. the effect of leaving group on rates has been investigated by changing the substituent in the leaving group from $4-\mathrm{NO}_{2}$ to $4-\mathrm{CHO}^{4} 4-\mathrm{COCH}_{3}$ and $4-$ $\mathrm{Cl}$. The second-order rate constants for the reaction of 
substituted phenyl 2-thiophenecarboxylates with piperidine are summarized in Table 3 . One can see that the reactivity of these esters towards piperidine increases with increasing electron withdrawing ability of the substituent in the leaving group, e.g., the second-order rate constant increases from $0.0025 \mathrm{M}^{-1} \mathrm{~s}^{-1}$ to $5.88 \mathrm{M}^{-1} \mathrm{~s}^{-1}$ as the substituent in the leaving group changes from a weak electron withdrawing group (4$\mathrm{Cl}$ ) to a strong one (4-NO ). A similar result can be seen for the reaction of substituted phenyl 2-furoates with piperidine.

The effect of the substituent in the leaving group on second-order rate constants has been demonstrated in Figure 3. It is demonstrated that $\sigma$ constants give good Hammett correlations for the reaction of piperidine with substituted phenyl 2-thiophenecarboxylates and with substituted phenyl 2 -furoates with a large $\rho^{-}$value (e.g. $\rho^{-}=3.11$ for the reaction of aryl 2-thiophenecarboxylates and $\rho^{-}=2.88$ for the reaction of aryl 2-furoates). The $\sigma$ constants have been used for a reaction in which a partial negative charge. which can be delocalized to the substituent by direct resonance. develops on the reaction center. In an aminolysis of carboxylic esters, development of such a partial negative charge is possible only when the leaving group departure is involved in the RDS. If the leaving group departure occurs at the RDS, a partial negative charge would develop at the $\mathrm{O}$ atom of the leaving aryloxide. Such a partial negative charge can be delocalized to the substituent in the leaving group (e.g.. 4$\mathrm{NO}_{2}$. $4-\mathrm{CHO}, 4-\mathrm{COCH}_{3}$ ) by direct resonance. Therefore. the fact that $\sigma$ constant gives a good Hammett correlation as shown in Figure 3 suggests that the present aminolysis proceeds through an addition intermediate in which the leaving group departure occurs at the RDS.

The magnitude of $\rho^{-}$value has been suggested to represent a measure of relative degree of bond break at the TS ${ }^{15}$ The large $\rho^{-}$value obtained in the present system (e.g. $\rho^{-}$value of 2.88 and 3.11 for the reaction of $1 \mathrm{a}$ and $1 \mathrm{~b}$, respectively) suggests that the degree of leaving group departure is significantly advanced at the rate-determining TS. This argument is consistent with the preceding proposal that the present aminolyses proceed through an addition intermediate and the leaving group departure from the intermediate is the RDS based on the $\beta_{\text {nuc }}$ values.

\section{Conclusions}

The present study allows us to conclude the following: (1) The replacement of the $\mathrm{CH}=\mathrm{CH}$ group by a sulfur or an oxygen atom in the acyl moiety $(\mathbf{1 c} \rightarrow \mathbf{1 a}$ or $1 \mathrm{c} \rightarrow \mathbf{1 b})$ increases reactivity as well as the acidity of the parent acid. 2-thiophenecarboxylic and 2-furoic acid. (2) The Bronstedtype plots for the aminolysis of $\mathbf{1 a - c}$ are linear, and the Hanmett plots with $\sigma^{-}$constants give better correlation than the ones with $\sigma$ constants for the reactions of piperidine with substituted phenyl 2-thiophenecarboxylates and substituted phenyl 2-furoates. (3) The aminolyses of 1 a-c proceed through a stepwise mechanism in which the leaving group departure from the addition intermediate to the products is the RDS, and the degree of bond breaking at the ratedetermining TS is significantly advanced.

Acknowledgment. This paper was supported by a grant from KOSEF (2000-123-02-2) and by a short time oversea training grant from Dong-A University in 2001 (JPL).

\section{References}

1. (a) Stefanidis, D.: Cho. S.; Dhe-Paganon. S.: Jencks, W. P. J. Am. Chent Soc. 1993. 115. 1650. (b) Jencks. W. P.: Brant. S. R.: Gandler. J. R.: Fendrich. G.: Nakamura. C. J. Am. Chem. Soc. 1982. 104. 7045. (c) Hupe. D. J. Jencks. W. P. J. Am Chem. Soc. 1977. 99, 451. (d) Jencks, W. P. Catalysis in Chemisty and Enzymology; MoGraw-Hill Book Company: New York. 1969; pp 463 .

2. (a) Oh. H. K.: Jeong. T. Bull. Korean Chem. Soc. 2001. 22. 1123 (b) Oh. H. K.: Park. C. Y.: Lee. T. M.: Lee. I. Bull. Korean Chen. Soc. 2001. 22. 383. (c) Oh. H. K.: Woo. S. Y.: Shin. C. H.: Park. Y. S. Lee I. J. Org Chem 1997, 62, 5780. (d) Koh. H. J. Lee. J. W: Lee. H. W. Lee. I. New J. Chem. 1997. $21,47$.

3. (a) Castro, E. A. Chem Rev 1999. 99. 3505. (b) Castro, E. A.: Cubillos. M.: Santos. J. G. J. Ong. Chent 1998. 63. 6820. (c) Castro. E. A.: Cubillos. M.: Santos. J. G. J. Ong. Chent 1996. 61. 3501. (d) Castro. E. A.: Araneda. C. A. J. Org. Chent 1997. 62. 126.

4. (a) Williams, A. Chem Soc. Rev 1994. 23, 93 . (b) Ba-Saif. S. Luthra. A. K.: Williams. A. J. Am. Chem. Soc. 1989, 111, 2647.

5. (a) Okuyama. T: Takano. H.: Senda. K. Bull. Chem. Soc. Jpn. 1996. 69. 2639. (b) DeTar. D. F. J. Ant Chen Soc. 1982. 10t. 7205 .

6. (a) Techniques of Organic Chemistry, th ed: Bernasconi, C. F., Ed.: Wiley: New York. 1986: vol. 6. (b) Chapman. N. B.: Shorter, J. Adrances in Linear Free Energy Relationships: Plenum: London. 1972.

7. (a) Un1. I. H.: Min. J. S.: Ahn1. J. A.: Hahn1. H. J. J. Org. Chent. 2000. 65. 5659. (b) Lee. I. P.: Yoon1. J. H.: Unn. I. H. Bull. Korean Chem Soc. 1999, 20.805. (c) Um, I. H.: Park, Y. M.; Shin, E. H. Bull. Koman Chem. Soc. 1999, 20. 392. (d) Um, I. H.; Chung. E. K. Lee. S. M. Con. J. Chem 1998. 76. 729. (e) Um, I. H: Yeom. E. S.: Kwon. H. T.: Kwonl. D. S. Bull. Korem Chem. Soc. 1997. 18. 865. (f) Um. I. H.: Chung. E. K.: Kwon. D. S. Tetrohedon Lett. 1997. 38. 4787, (g) Um. I. H.: Hong. Y. J.: Kwon. D. S. Tetahedron 1997, 53,5073 .

8. (a) Colthurst, M. J.: Williams, A. J. Chem. Soc., Perhin Trans. 2 1997. 1493. (b) Castro, E. A.; Valdiva, J. L. J. Org. Chem 1986. 51. 1668. (c) Castro. E. A.: Santander. C. L. J. Org. Chem. 1985. 50. 3595. (d) Castro. E. A.: Steinfort. G. B. J Chent. Soc., Perkin Trans. II 1983. 453. (e) Menger. F. M.: Stnith. T. H. J. Ant Chent. Soc. $1972,94,3824$.

9. (a) Correla, V. R.: Cuccovia, I. M.: Chaimovich. H. J. Plns. Org. Chem. 1991. f, 13 . (b) Kirsch. J. F: Clewell. W. Simon, A. J. Org. Chent 1968. 33. 127. (c) Caplow. M.: Jenchs. W. P. Biochentistiv 1962. l. 883.

10. Vogel. A. I. Practical Orgamic Chemism: Longman's Green and Co.: London. 1962: p 792.

11. Albert. A. Phusical Methods in Heterocychic Chemisny. Katritzky. A. R., Ed.: Academic Press: London, 1963, Vol. 1, p 4.

12. Tenchs. W. P. J. Am. Chem. Soc 1989. H1]. 8479

13. Unn. I. H.: Min. I. S.: Lee. H. W. Can. J. Chent 1999. 77. 659.

14. Unn. I. H.: Kwon. H. J.: Kwon. D. S.: Park. T. Y. J. Chen. Res (s) 1995. 301; d. Chem. Res. fitf 1995. 1801

15. Buncel. E.; Um, I. H.; Hoz. S. J. Am. Chem. Soc. 1989. 111. 971.

16. Jones. R. A. Y. Physical and Mechanistic Organic Chemisny and ed: Cambridge University Press: London. 1984: p 65. 